Article

\title{
Centralized and Decentralized Recycle Policy with Transboundary Pollution
}

\author{
Chien-Hui Lee ${ }^{1}$, Po-Sheng Ko ${ }^{2, *}$, Yu-Lin Wang ${ }^{3, *}$, Jen-Yao Lee ${ }^{1, *}$ (I) and Jiong-Hung Kwo ${ }^{4}$ \\ 1 Department of International Business, National Kaohsiung University of Science and Technology, \\ Kaohsiung 80778, Taiwan; chlee@nkust.edu.tw \\ 2 Department of Public Finance and Taxation, National Kaohsiung University of Science and Technology, \\ Kaohsiung 80778, Taiwan \\ 3 Department of Economics, National Chung Cheng University, Chiayi 621301, Taiwan \\ 4 School of Management and Economics, Kunming University of Science and Technology, Kunming 650559, \\ China; kwo8112357@hotmail.com \\ * Correspondence: psko@nkust.edu.tw (P.-S.K.); ecdylw@ccu.edu.tw (Y.-L.W.); itjylee@nkust.edu.tw (J.-Y.L.)
}

Received: 21 April 2020; Accepted: 21 May 2020; Published: 24 May 2020

\begin{abstract}
In this study, under the existence of unilateral cross-border environmental pollution in two regions, a complete information dynamic game theory is constructed to discuss the environmental policy (recycling fee and treatment subsidy) formulation of the central government by two local governments. As a result, it was found that the spillover effect will reduce the level of social welfare. At the same time, the intervention of the central government and the adoption of policies tailored to local conditions will be conducive to the improvement of social welfare.
\end{abstract}

Keywords: transboundary pollution; recycle policy; recycling fee; treatment subsidy

\section{Introduction}

Promoting the sustainable development of the environment through pollution intervention and emission reduction is an important environmental and economic issue. Among these, resource recycling is an act of pollution reduction, and at the same time, the waste obtained through resource recycling is properly processed to create economic value.

There are four general approaches to environmental law and regulation-(i) liability schemes; (ii) command-and-control; (iii) market structure strategies (strategies for developing or defining a market, such as take-back legislation); and (iv) market-based strategies [1]. In addition to the aforementioned research, Coase [2] emphasized the importance of property right and bargaining between polluters and victims to solve environmental problems.

There are several different directions in promoting the recycling of resources in the developed countries. In the United States, the implementation of resource recycling focuses on the development of a resource-waste recycling raw material market, supplemented by mandatory laws. In order to implement recycling systems, most countries have adopted the concept of expanding producer responsibility; for example, Germany has successfully developed a dual recycling system [3]. In Asia, resource circulation and management are widely valued by countries. Hotta and Kojima [4], and Totoki et al. [5] conducted a complete review of the recycling systems in Asian countries. In Taiwan, recycling was originally incorporated into the Waste Disposal Act in 1987 and made clear changes to change the system from privatization to nationalization in 1998 and 2002. The current structure is built on six main bodies - the management committee; consumers; responsible industries; collection and treatment agents; the Collection, Disposal, and Treatment Fee Reviewing Committee (CDT Fee Reviewing Committee); and auditing agents. Under this framework, the auditing agents are judicial 
third parties that sign a contract with the management committee and are responsible for reviewing the submission of fees and subsidiary applications [6].

In China, the "Environmental Prevention and Control Law of Solid Waste Pollution" was enacted in 1995 and marked the beginning of waste management; the 2002 SARS (Severe acute respiratory syndrome) incident accelerated the development of medical hazardous waste in China and was an important milestone in the development of waste management. In 2004, the "Environmental Prevention and Control Law of Solid Waste Pollution" began to be revised; at this time, waste management in China entered a stage of development. The "Regulations for the Management of the Recycling of Waste Electrical Appliances and Electronic Products" (referred to as Regulations) promulgated in 2009 (effective in 2011) includes two aspects of "renewable resources" and "environmental protection," creating a new opportunity for the resource recycling industry. According to Article 7 in the Regulations, the state established a waste electrical and electronic product disposal fund and used it to subsidize the recycling of waste electrical and electronic products. The fund is a national fund and is levied using the national tax system; at the same time, unified subsidies are provided.

In 2013, the Ministry of Environmental Protection confirmed a total of 39.87 million sets of various types of waste electrical and electronic products; in 2018, it had reached 81 million sets. Among them, the main processing areas are concentrated in Jiangsu, Sichuan and Zhejiang; however, the main production areas of electrical appliances, taking TVs as an example, are in Guangdong (TCL, Skyworth), Shandong (Hisense), and Sichuan (Changhong).

Before the law was revised, the established waste recycling system in China was dominated by local governments. For example, since 2007, Beijing has comprehensively constructed an electronic waste recycling system in eight urban areas. The recycling network will be used by Beijing's electronic waste treatment enterprises to recycle used household appliances, and the government will provide an average subsidy of 140 yuan per unit. In 2006, Shanghai launched the "Interim Regulations on the Recycling of Waste Electrical and Electronic Appliances in Shanghai," which will oblige households to scrap household appliances that have exceeded their use period, and the government will give owners 30-50 yuan in economic compensation per unit [7].

We can find that, before the amendment of Regulations, recycling policy was dominated by local governments. However, after the amendment of Regulations, recycling policy has been led by the central government and is consistent across the country. Due to the characteristics of the Chinese administrative system, the process of system transition is an important issue where either the central or local government dominates recycling policies. In addition, the transboundary pollution caused by the different locations of the production and polluting areas has led to the failure of environmental policies and has become a topic that has gained attention in practical and theoretical circles in recent years.

In past research, it was mainly believed that both production and contaminated sites would be in the same place, although recent studies suggest that the pollution caused by the production site may be through some media, so that the production and contaminated sites are not in the same area. Taking household electrical appliances as an example, household electrical appliances produced in Shanghai may be sold to Beijing, which may cause environmental pollution (cross-border pollution) in Beijing; however, for the fees paid by the waste-responsible person (product manufacturer), these enter Shanghai's government revenue, resulting in an asymmetric responsibility for fiscal revenue and environmental protection burden. Therefore, how to formulate environmental policies is an important issue in cross-border pollution.

There are several problems in the formulation of environmental policies for cross-border pollution. First of all, when local governments formulate policies, they may only consider their local social welfare to formulate the best environmental policy, which not only lacks a comprehensive consideration of national social welfare but also lacks policy coordination among local governments. At the same time, the optimal environmental policy setting for the local government is not the same as the optimal environmental policy for the central government. In terms of local standardization, it may cause 
excessively strict (or loose) environmental policies, which are not conducive to the economic growth of the entire society or consumer protection.

Second, taking the example of household appliances, local governments have the same administrative level, and due to insufficient horizontal coordination of local governments, they may generate unequal fiscal revenue or fail to implement environmental protection policies.

Third, the market size or production efficiency of the two regions might be different, and the environmental policies of the two local governments will also be different, which will affect consumer welfare, producer profits, environmental damage, and government revenue. However, due to the existence of cross-border pollution, the effects of urban environmental policies will spill over to other cities. The policy coordination between local governments is even more important; therefore, research on the formulation of environmental policies by the central government and local governments is also very important, which also stimulated the research focus of this article.

This paper is organized as follows. In Section 2, we provide a summary of the literature related to environmental (taxation, recycling and subsidy) policies. In Section 3, the model and results of environmental policy without transboundary pollution are provided. Next, we study the case of environmental policy with transboundary pollution in Section 4 . Section 5 concludes the paper.

\section{Literature Review}

In the study of environmental taxation and subsidy policies, Pigou [8] proved that in a competitive industrial structure, the optimal pollution tax rate should be equal to the marginal damage of environmental pollution, which is called "Pigouvian tax" in the literature. However, Buchanan [9] determined that in an exclusive industrial structure, under the second-best policy, the government's optimal pollution tax rate should be lower than the marginal damage of environmental pollution. Smith [10], Barnett [11], Oates and Strassmann [12], and Misiolek [13] also pointed out that the optimal Pigouvian tax should not be equal to the cost of marginal damage.

Simpson [14] derived the optimal pollution for a Cournot duopoly and found that if firms have different production costs, the optimal tax rate may exceed the marginal damage. Long and Soubeyran [15] considered an asymmetric polluting oligopoly and demonstrated that optimal tax rates per unit of emission are not the same for all firms. They found that efficient tax structure requires that high-cost firms pay a higher tax rate.

The literature also discusses pollution taxes and pollution prevention. Empirical analysis by Downing and White [16] and Milliman and Prince [17] determined that the collection of pollution tax will induce manufacturers to be more willing to invest in non-polluting equipment, while Conrad and Wang [18] concluded that under different market structures, the increase in pollution tax will reduce the total amount of pollution. At the same time, the prevention and control cost subsidies are indeterminant vis-à-vis the change in pollution. Damania [19] uses the game to analyze that, even in the case of pollution tax collection, manufacturers may not have the willingness to purchase pollution prevention equipment, while Yin [20] considers the mutual influence of pollution tax and pollution prevention amount among manufacturers under the effect of pollution spillover. In a free-entry modeling, Lahiri and Ono [21], Fujiwara [22], and Wang et al. [23] showed that environmental policy in the short- and long-run is highly sensitive to the demand function and the presence of free entry.

The shortcomings of the Pigouvian tax are that the government must pay a huge cost to monitor polluting behavior and measure the pollution level, which causes difficulties in implementation [24]. Therefore, some scholars have proposed a two-part instrument; that is, the manufacturer is taxed in accordance with the output, and after the product is used, the amount of waste is increased by means of recycling subsidies. Fullerton and Wolverton [25] verified that the implementation of the two-stage policy tool could achieve the same effect as the Pigouvian tax. Setting up a recycling and disposal fund to collect fees from responsible operators to pay for subsidies required by the recycling market can theoretically be regarded as a product charge. Palmer and Walls [26] believed that this system has the following three advantages: first, it could reduce the financial burden; second, there is a mechanism to 
prevent the production of the industry; third, the subsidy for the recycling market could encourage the application of renewable substances.

Under the globalization of trade, more and more scholars are concerned about the impact of environmental pollution caused by cross-border economics, as in, for example, studies by Ludema and Wooton [27], Copeland and Taylor [28], Copeland [29], Antweiler et al. [30], Benarroch and Thille [31], Lai and Hu [32], Ferrara et al. [33], Bhattacharya and Pal [34], Lapan and Sikdar [35], and Yang and $\mathrm{Xu}$ [36]. The spillover effects caused by cross-border pollution have received extensive attention in international trade policies, although domestic policy coordination caused by cross-regional pollution is relatively lacking in discussions. However, for super-large countries or economic zones such as mainland China, the United States, or the European Union, regional environmental coordination within the territory is very important.

At present, China has not established a "complete" e-products recycling system. According to China's WEEE regulations, dismantling of electronic products must go through a strict review by the environmental protection department, and a disassembly qualification certificate will be issued thereafter [37]. Shinkuma and Managi [38] discussed the e-waste recycling license scheme in China and India and showed that if the law does not prohibit disposers of -waste from selling to unlicensed recyclers, the license scheme does not work effectively. Sugeta and Shinkuma [39] considered the environmental effects of trade in recycled materials between two countries and showed that the heterogeneity in the recovery rates between two countries played an important role. Liu et al. [40] studied the competition between the formal and informal sectors and showed that the subsidies can increase the acquisition quantity of used products in the formal sector, but the increase will slow down with higher subsidy. If the recycling fee that producers are charged is small, social welfare will be improved. In addition, the influence of the recycling fee on the social welfare will be nonlinear. Liu et al. [41] discussed the influence of the fund policy on the social welfare by employing a game model and simulated a new fund reduction policy to achieve multiplayer objective optimization. They believed that the fund policy may cause a trade-off between remanufacturing profits and the economic burden of primary manufacturers. Shih et al. [42] argued that differential subsidy rates in the recycling fund management system can help encourage greater effort for a cleaner environment.

However, there are few studies on the multi-regional recycling fund management system and the coordination of environmental policies between central and local governments. Ma et al. [43] believe that the current cross-administrative environmental problems in mainland China are very prominent, and the establishment of a cross-administrative environment management coordination mechanism is insufficient. As mentioned above, the coordination between the central government and local governments is very important for the cross-regional pollution of Beijing and Shanghai and the formulation of their environmental policies.

\section{Environmental Policy without Transboundary Pollution}

\subsection{The Model}

Suppose there is one firm of electronic products in the electronic industry in each region $i$. The output is $q_{i}, i=\mathrm{A}, \mathrm{B}$, and its marginal cost of production is $c$. This product has pollution after consumption (such as waste electrical appliances and electronic products), and we assume the amount of pollution after consuming is $e=\theta$. The demand function is $p_{i}=a_{i}-b q_{i}$, where $a_{i}$ and $p_{i}$ are the market size and price of region $i$, respectively, and $a_{A}>a_{B}$ indicate that the market sizes are asymmetrical.

Suppose the government charges a collection, disposal, and treatment fee (namely recycling fee) of $t_{i}$ to the manufacturers for the output of each unit, and at the same time, subsidies to the collection and treatment agents (namely recyclers), then each unit will give a treatment subsidy $s_{i}$. At this time, for the recycler in the market, the resource recovery amount is $x_{i}$, and the treatment cost is $\rho x_{i}^{2} / 2$. In addition to the government-subsidized treatment subsidy of $s_{i}$, after the recovered waste is processed, it can be 
sold at a price of $r$ per unit (assuming the international recycling material price), then the profits of the recyclers and manufacturers are as follow:

$$
\begin{gathered}
\pi_{A}^{R}=\left(r+s_{A}\right) x_{A}-\rho x_{A}^{2} / 2 \\
\pi_{B}^{R}=\left(r+s_{B}\right) x_{B}-\rho x_{B}^{2} / 2 \\
\pi_{A}^{M}=\left(P_{A}-c-t_{A}\right) q_{A}=\left(q_{A}-b q_{A}-c-t_{A}\right) q_{A} \\
\pi_{B}^{M}=\left(p_{B}-c-t_{B}\right) q_{B}=\left(q_{B}-b q_{B}-c-t_{B}\right) q_{B}
\end{gathered}
$$

Assuming that there is no cross-border pollution, the environmental damage is $D_{i}=\theta\left(q_{i}-x_{i}\right)$, and the social welfare of the two regions A and B is the sum of consumer surplus (CS), manufacturers and recyclers profits, and environmental damage can be expressed as

$$
\begin{gathered}
W_{A}=C S_{A}+\pi_{A}^{R}+\pi_{A}^{M}-s_{A} x_{A}+t_{A} q_{A}-\theta\left(q_{A}-x_{A}\right) \\
W_{B}=C S_{B}+\pi_{B}^{R}+\pi_{B}^{M}-s_{B} x_{B}+t_{B} q_{B}-\theta\left(q_{B}-x_{B}\right)
\end{gathered}
$$

A two-stage game is built to explore the recycling fee and the treatment subsidy. In the first stage, the government decides to collect the recycling fee $(t)$ and the treatment subsidy $(s)$; in the second stage, the resource recycler and the electronic manufacturer determine their optimal recycling amount $(x)$ and electronic production $(q)$. With the Subgame Perfect Nash Equilibrium (SPNE), the backward induction is adopted to solve the game.

\subsection{Environmental Policy with Decentralized Policy Makers}

This section assumes that officials of each region decide the environmental policy of the region on their own. This is a decentralized policy decision-making model.

\subsubsection{Market Stage}

Taking differentiation on Equations (1)-(4) with respect to $q_{i}$ and $x_{i}$, the first-order conditions for choosing the output of the electronic manufacturers and the resource recovery amount of the recyclers are as follow:

$$
\begin{gathered}
\frac{\partial \pi_{A}^{M}}{\partial q_{A}}=a_{A}-c-2 b q_{A}-t_{A}=0 \\
\frac{\partial \pi_{B}^{M}}{\partial q_{B}}=a_{B}-c-2 b q_{B}-t_{B}=0 \\
\frac{\partial \pi_{A}^{R}}{\partial x_{A}}=r+S_{A}-\rho x_{A}=0 \\
\frac{\partial \pi_{B}^{R}}{\partial x_{B}}=r+S_{B}-\rho x_{B}=0
\end{gathered}
$$

The second order conditions are hold if $2 b \rho>0$. Solving Equations (7)-(10) simultaneously, we have

$$
\begin{gathered}
q_{A}^{M}(t)=\frac{1}{2 b}\left(a_{A}-c-t_{A}\right) \\
q_{B}^{M}(t)=\frac{1}{2 b}\left(a_{B}-c-t_{B}\right) \\
x_{A}^{R}(s)=\frac{r+s_{A}}{\rho} \\
x_{B}^{R}(s)=\frac{r+s_{B}}{\rho}
\end{gathered}
$$


Equations (11)-(14) indicate the reaction functions of the electronic manufacturers and the recyclers.

\subsubsection{Policy Stage}

The optimal environmental policy and market equilibrium solution for individual regions:

(1) The Equilibrium of Region A

Assume that the government's object is to maximize social welfare in Equation (5), and at the same time, the government has complete information on the behavior of electronic manufacturers and recyclers, the government will know the reaction function of the firms, $q_{A}^{M}(t)=q(t)$ and $x_{A}^{R}(s)=x(s)$, and at this time the government's decision problem can be expressed as

$$
\max _{s, t} W_{A} \text { st. } q_{A}^{M}(t)=q(t), x_{A}^{R}(s)=x(s)
$$

Taking differentiation on Equation (15) with respect to $t_{A}$ and $s_{A}$, the optimal recycling fee and treatment subsidy are obtained from the following first-order condition:

$$
\begin{gathered}
\frac{\partial W_{A}}{\partial t_{A}}=-\frac{a_{A}-c+t-2 \theta}{4 b}=0 \\
\frac{\partial W_{A}}{\partial s_{A}}=\frac{1}{\rho}\left(-s_{A}+\theta\right)=0
\end{gathered}
$$

The second order conditions hold if $\frac{1}{4 b \rho}>0$. From Equations (16) and (17), $t_{A}^{*}$ and $s_{A}^{*}$ are

$$
\begin{gathered}
t_{A}^{*}=-a_{A}+c+2 \theta>0, \text { if }\left(a_{A}-c\right) / 2<\theta, \\
s_{A}^{*}=\theta .
\end{gathered}
$$

The output of the electronic manufacturers and the resource recovery amount of the resource recycling firms are as follow:

$$
q_{A}^{*}=\frac{a_{A}-c-\theta}{b}, x_{A}^{*}=\frac{r+\theta}{\rho}
$$

From Equations (18) and (19), we obtain Lemma 1 immediately.

Lemma 1. The equilibria in region $A$ are

$$
\begin{gathered}
p_{A}^{*}=c+\theta, Q_{A}^{*}=\frac{a_{A}-c-\theta}{b}, \\
\pi_{A}^{M *}=\frac{\left(a_{A}-c-\theta\right)^{2}}{b}, \pi_{A}^{R *}=\frac{(r+\theta)^{2}}{2 \rho}, \\
W_{A}^{*}=\frac{b(r+\theta)^{2}+\left(a_{A}-c-\theta\right)^{2} \rho}{2 b \rho} .
\end{gathered}
$$

(2) The Equilibrium of Region B

In the same way, we can solve the equilibrium outcomes of Region B, the government's object is to maximize social welfare in Equation $(6), t_{B}^{*}$ and $s_{B}^{*}$ are

$$
\begin{gathered}
t_{B}^{*}=-a_{B}+c+2 \theta>0, \text { if }\left(a_{B}-c\right) / 2<\theta, \\
s_{B}^{*}=\theta .
\end{gathered}
$$

The output of the electronic manufacturers and the resource recovery amount of the resource recycling firms are as follow:

$$
q_{B}^{*}=\frac{a_{B}-c-\theta}{b}, x_{B}^{*}=\frac{r+\theta}{\rho}
$$


From Equations (20) and (21), we obtain Lemma 2 immediately.

Lemma 2. The equilibria in region $B$ are

$$
\begin{gathered}
p_{B}^{*}=c+\theta, Q_{B}^{*}=\frac{a_{B}-c-\theta}{b}, \\
\pi_{B}^{M *}=\frac{\left(a_{B}-c-\theta\right)^{2}}{b}, \pi_{B}^{R *}=\frac{(r+\theta)^{2}}{2 \rho}, \\
W_{B}^{*}=\frac{b(r+\theta)^{2}+\left(a_{B}-c-\theta\right)^{2} \rho}{2 b \rho}
\end{gathered}
$$

Comparing the equilibria of the two regions $\mathrm{A}$ and $\mathrm{B}$, it can be found that $t_{B}^{*}>t_{A}^{*}$ indicates that the recycling fee of region $A$ will be less than that of region $B$, mainly due to the larger market size of region $\mathrm{A}$ and the higher marginal benefits of the products, so the product has a higher tolerance to pollution in the market, and a lower recycling fee will be set to encourage manufacturers to produce more. However, since the marginal damage per unit of pollution of the products in the two regions is the same, the recycling fee will be the same.

Proposition 1. The recycling fee set by the region with a large market size will be lower than the region with a small market size; but the treatment subsidies are the same in both regions.

\subsection{Environmental Policy with a Centralized Policy Maker}

This section assumes that the regional environmental policy of each region must be formulated by the central government. This is a centralized policy decision-making model. Two cases are considered here. In the first case, the central government adopts a nationally consistent environmental policy; in the second case, the central government adopts an environmental policy adapted to local conditions.

\subsubsection{Nationally Consistent Environmental Policy}

Assuming that the central government attaches the same importance to the social welfare of the two regions, the total social welfare of the two regions will be maximized at this time. The objective function can be expressed as

$$
W=W_{A}+W_{B}
$$

Due to the nationally consistent environmental policy, we have $t_{A}=t_{B}=t$, and $s_{A}=s_{B}=s$.

Taking differentiation on Equation (22) with respect to $t$ and $s$, the optimal recycling fee and treatment subsidy are obtained from the following first-order condition:

$$
\begin{gathered}
\frac{\partial W}{\partial t}=-\frac{a_{A}+a_{B}-2 c+2 t-4 \theta}{4 b}=0 \\
\frac{\partial W}{\partial s}=-\frac{2(s-\theta)}{\rho}=0
\end{gathered}
$$

From Equations (23) and (24), $t^{U *}$ and $s^{U_{*}}$ are (denoted by $U$ on superscript for centralized policy with uniform rate)

$$
\begin{gathered}
t^{U *}=\frac{1}{2}\left(2 c+4 \theta-a_{A}-a_{B}\right)>0, \text { if } \frac{1}{4}\left(a_{A}+a_{B}-2 c\right)<\theta ; \\
{ }_{S}{ }^{* *}=\theta .
\end{gathered}
$$

Comparing Equations (18), (20) and (25), the recycling fees set by the central government and the two local governments separately, we obtain

$$
t_{A}^{*}<t^{U *}<t_{B}^{*}
$$


From Equation (26), we have the following proposition.

Proposition 2. When the central government adopts a nationally consistent policy, the recycling fee it stipulates will be between the recycling fees set separately by the two regions; however, the treatment subsidies are the same.

Proposition 2 indicates that when the central government adopts a nationally consistent policy, the market size of the two regions is not the same. As stated in Proposition 1, for the region with a large market size, the government sets a low recycling fee; for the region with a small market size, the government sets a high recycling fee. Therefore, the central government can only set the recycling fee for its average market size. Naturally, the optimal recycling fee set by the central government will be between the recycling fees set by the local government of two regions.

\subsubsection{Environmental Policies Adapted to Local Conditions}

Due to the environmental policies adapted to local conditions, the central government chooses the $t_{A}, t_{B}, s_{A}$ and $s_{B}$ to maximize total social welfare.

The optimal recycling fee and treatment subsidy are obtained from the following first-order conditions:

$$
\begin{gathered}
\frac{\partial W}{\partial t_{A}}=-\frac{a_{A}+t_{A}-c-2 \theta}{4 b}=0 \\
\frac{\partial W}{\partial t_{B}}=-\frac{a_{B}+t_{B}-c-2 \theta}{4 b}=0 \\
\frac{\partial W}{\partial s_{A}}=\frac{1}{\rho}\left(\theta-s_{A}\right)=0 \\
\frac{\partial W}{\partial s_{B}}=\frac{1}{\rho}\left(\theta-s_{B}\right)=0
\end{gathered}
$$

From Equations (27)-(30), $t_{i}^{D *}$ and $s_{i}^{D *}$ are (denoted by $D$ on superscript for centralized policy with discriminatory rate)

$$
\begin{gathered}
t_{A}^{D *}=-a_{A}+c+2 \theta>0, \text { if }\left(a_{A}-c\right) / 2<\theta ; \\
t_{B}^{D *}=-a_{B}+c+2 \theta>0, \text { if } \frac{a_{B}-c}{2}<\theta ; \\
s_{A}^{D *}=s_{B}^{D *}=\theta .
\end{gathered}
$$

From Equation (31), we obtain proposition 3 immediately.

Proposition 3. When the central government adopts a policy that is tailored to local conditions, the recycling fees set by it will be equal to the recycling fees individually set by the local government of two regions, and the subsidies are the same.

Similarly, comparing the equilibria of the two regions $\mathrm{A}$ and $\mathrm{B}, t_{B}^{D *}>t_{A}^{D *}$ indicates that the recycling fee of region $A$ will be less than that of region $B$, mainly due to the larger market size of region $A$ and the marginal benefit being higher, so the product is more resistant to pollution in the market, and the central government will set a lower recycling fee to encourage manufacturers to produce more. In other words, in light of local conditions, the policies set by the central government will return to maximizing local social welfare. Therefore, the optimal environmental policies set will be at the same level as the local governments.

\section{Environmental Policy with Transboundary Pollution}

\subsection{The Model}

As mentioned in Section 3, there is no cross-border pollution between the two regions, and their equilibrium variables do not affect each other. However, if there is cross-border pollution, 
this equilibrium may be disrupted. For example, the electronic products produced in Beijing are sold to Shanghai, and the waste electronic products are discarded in Shanghai. In the case of payment in Shanghai, the optimal policies of the local government will deviate from the level of social welfare maximization. Therefore, the formulation of the optimal environmental policy can only be applied after the model is revised.

To simplify the analysis, we discuss the unilateral cross-border pollution caused by region A to region $B$. Assuming that the ratio of products that produce cross-border pollution from region $A$ to region $B$ is $\delta_{A}$, the pollution rate for its own region is $1-\delta_{A}$, and the welfare function of the two regions can be modified as

$$
\begin{gathered}
W_{A}=C S_{A}+\pi_{A}^{D}+\pi_{A}^{U}-s_{A} x_{A}+t_{A} q_{A}-\theta\left(\left(1-\delta_{A}\right) q_{A}-x_{A}\right) \\
W_{B}=C S_{B}+\pi_{B}^{D}+\pi_{B}^{U}-s_{B} x_{B}+t_{B} q_{B}-\theta\left(q_{B}+\delta_{A} q_{A}-x_{B}\right)
\end{gathered}
$$

\subsection{Environmental Policy with Decentralized Policy Makers}

The optimal environmental policy and market equilibrium solution for individual regions are as follows:

(1) The Equilibrium of Region A

Taking differentiation on Equation (32) with respect to $t_{A}$ and $s_{A}$, the optimal recycling fee and treatment subsidy are obtained from the following first-order condition:

$$
\begin{gathered}
\frac{\partial W_{A}}{\partial t_{A}}=\frac{-2 \rho a_{A}+\rho\left(2 c+4 \theta-t_{A}\right)-\rho t_{A}-4 \theta \rho \delta_{A}}{8 b \rho}=0 \\
\frac{\partial W_{A}}{\partial s_{A}}=\frac{\theta-s_{A}}{\rho}=0
\end{gathered}
$$

From Equations (34) and (35), $\hat{t}_{i}$ and $\hat{s}_{i}$ are

$$
\begin{gathered}
\hat{t}_{A}=c+2 \theta-a_{A}-2 \theta \delta_{A}>0, \text { if }\left(a_{A}-c\right) / 2\left(1-\delta_{A}\right)<\theta ; \\
\hat{s}_{A}=\theta
\end{gathered}
$$

The output of the electronic manufacturers and the resource recovery amount of the resource recycling firms are as follow:

$$
\begin{gathered}
\hat{q}_{A}=\frac{a_{1}-c-\theta+\theta \delta_{1}}{b}, \\
\hat{x}_{A}=\frac{r+\theta}{\rho} .
\end{gathered}
$$

From Equations (36) and (37), we obtain Lemma 3 immediately.

Lemma 3. With transboundary pollution, the equilibrium in region $A$ are with decentralized policy makers

$$
\begin{gathered}
\hat{p}_{A}=c+\theta-\theta \delta_{A}, \hat{Q}_{A}=\frac{a_{A}+\theta \delta_{A}-c-\theta}{b}, \\
\hat{\pi}_{A}^{M}=\frac{\left(c+\theta-a_{A}-\theta \delta_{A}\right)^{2}}{b}, \hat{\pi}_{A}^{R}=\frac{(r+\theta)^{2}}{2 \rho}, \\
\hat{W}_{A}=\frac{b(r+\theta)^{2}+(c+\theta)^{2} \rho-\rho\left(2(c+\theta)-a_{A}-\theta \delta_{A}\right)\left(a_{A}+\theta \delta_{A}\right)}{2 b \rho}
\end{gathered}
$$

(2) The Equilibrium of Region B

In the same way, we can solve the equilibrium outcomes of Region B, the government's object is to maximize social welfare in Equation (33). The optimal recycling fee and treatment subsidy are obtained from the following first-order condition: 


$$
\begin{gathered}
\frac{\partial W_{B}}{\partial t_{B}}=\frac{-2 \rho a_{B}+\rho\left(2 c+4 \theta-t_{B}\right)-\rho t_{B}}{8 b \rho}=0 \\
\frac{\partial W_{B}}{\partial S_{B}}=\frac{1}{\rho}\left(-s_{B}+\theta\right)=0
\end{gathered}
$$

From Equations (39) and (40), $\hat{t}_{i}$ and $\hat{s}_{i}$ are

$$
\begin{gathered}
\hat{t}_{B}=c+2 \theta-a_{B}>0, \text { if }\left(a_{B}-c\right) / 2<\theta ; \\
\hat{s}_{B}=\theta .
\end{gathered}
$$

The output of the electronic manufacturers and the resource recovery amount of the resource recycling firms are as follow:

$$
\begin{gathered}
\hat{q}_{B}=a_{B}-c-\theta, \\
\hat{x}_{B}=\frac{r+\theta}{\rho}
\end{gathered}
$$

From Equations (41) and (42), we obtain Lemma 4 immediately.

Lemma 4. With transboundary pollution, the equilibrium in region B with decentralized policy makers is indicated as

$$
\begin{gathered}
\hat{p}_{B}=\frac{b(c+\theta)+(-1+b) a_{B}}{2 b-1}, \hat{Q}_{B}=\frac{a_{B}-c-\theta}{2 b-1}, \\
\hat{\pi}_{B}^{M}=\frac{b\left(c+\theta-a_{B}\right)^{2}}{(2 b-1)^{2}}, \hat{\pi}_{B}^{R}=\frac{(r+\theta)^{2}}{2 \rho}, \\
\hat{W}_{B}=\frac{(r+\theta)^{2}+b(c+\theta)^{2} \rho-2 b(c+\theta) \rho a_{B}+b \rho a_{B}^{2}+2 \theta \rho \delta_{A}\left(c+\theta-a_{A}-\theta \delta_{A}\right)}{2 \rho}
\end{gathered}
$$

Taking differentiation on Equation (38) with respect to $\delta_{A}$, we obtain

$$
\begin{gathered}
\frac{d \hat{t}_{A}}{d \delta_{A}}=-2 \theta<0, \\
\frac{d \hat{W}_{A}}{d \delta_{A}}=\frac{\theta\left(a_{A}-c-\theta\left(1-\delta_{A}\right)\right)}{b}>0, \text { if }\left(a_{A}-c\right) /\left(1-\delta_{A}\right)<\theta .
\end{gathered}
$$

From Equation (44), we have $\frac{d \hat{t}_{A}}{d \delta_{A}}<0$ and $\frac{d \hat{W}_{A}}{d \delta_{A}}>0$, if $\left(a_{A}-c\right) /\left(1-\delta_{A}\right)<\theta$. This result indicates that the lower the cross-border pollution ratio, the lower the optimal recycling fee and the higher the social welfare in area A. The main reason is that cross-border pollution reduces the local pollution level, and at the same time, the proportion of pollution left behind by each unit of production decreases, thus reducing the marginal damage to society, thus lowering the optimal recycling fee. On the other hand, when the proportion of cross-border pollution is higher, the direct effect will be appropriate to reduce the pollution of production to the environment and improve social welfare; the indirect effect will reduce the optimal recycling fees and increase the output of manufacturers, thus improving social welfare.

Taking differentiation on Equation (43) with respect to $\delta_{A}$, we obtain

$$
\frac{d \hat{W}_{B}}{d \delta_{A}}=\theta\left(c+\theta-a_{A}-2 \theta \delta_{A}\right)<0, \text { if }\left(a_{A}-c\right) /\left(1-\delta_{A}\right)<\theta .
$$

From Equation (45), we have $\frac{d \hat{W}_{B}}{d \delta_{A}}<0$, if $\left(a_{A}-c\right) /\left(1-\delta_{A}\right)<\theta$. This result indicates that when the proportion of cross-border pollution increases, the externalities caused by the production of manufacturers in Region A will not be corrected by the environmental policies of Region B, which will increase the social welfare in Region A and decrease the social welfare in Region B.

Proposition 4. When the recycling fees and the treatment subsidies are separately set by two regions; the cross-border pollution ratio will cause the recycling fee in region $A$ to decrease and region $B$ to remain unchanged; at the same time, social welfare in region $A$ has increased, while social welfare in region $B$ has declined. 


\subsection{Environmental Policy with a Centralized Policy Maker}

This section considers a centralized policy decision-making model. Two cases are considered here. In the first case, the central government adopts a nationally consistent environmental policy; in the second case, the central government adopts an environmental policy adapted to local conditions.

\subsubsection{Nationally Consistent Environmental Policy}

The optimal recycling fee and treatment subsidy are obtained from the following first-order condition:

$$
\begin{gathered}
\frac{\partial W}{\partial t}=-\frac{a_{A}+a_{B}-2 c+2 t-4 \theta}{4 b}=0 \\
\frac{\partial W}{\partial s}=-\frac{2(s-\theta)}{\rho}=0
\end{gathered}
$$

From Equations (46) and (47), $\hat{t}^{U}$ and $\hat{s}^{U}$ are: (denoted by $U$ on superscript for centralized policy with discriminatory rate)

$$
\begin{aligned}
\hat{t}^{U}=\frac{1}{2}\left(2 c+4 \theta-a_{A}-a_{B}\right) & >0, \text { if } \frac{1}{4}\left(a_{A}+a_{B}-2 c\right)<\theta ; \\
\hat{s}^{U} & =\theta .
\end{aligned}
$$

Comparing Equations (36), (41) and (48), the recycling fees set by the central government and the two local governments separately, we have

$$
\hat{t}_{A}<\hat{t}^{U}<\hat{t}_{B}
$$

From Equation (49), we have the following proposition.

Proposition 5. Under unilateral transboundary pollution, when the central government adopts a nationally consistent policy, it will be at the same level as non-transboundary pollution; the recycling fees set by it will be between the recycling fees set by the two regions, but at the same subsidy rate for treatment.

Proposition 5 indicates that when the central government adopts a nationally consistent policy, the optimal recycling fees are also different due to the different market sizes of the two regions. As mentioned in Proposition 2, for the region with a large market size, the government sets a low recycling fee; for the region with a small market size, the government sets a high recycling fee. Therefore, the central government can only set the recycling fee for its average market size. Naturally, the optimal recycling fee will be between the recycling fees set by the two regions. In addition, the situation of cross-border pollution cancels each other out in the central government's objective function. Therefore, it does not affect the determination of its optimal recycling fees.

\subsubsection{Environmental Policies Adapted to Local Conditions}

Due to the environmental policies adapted to local conditions, the central government chooses the $t_{A}, t_{B}, s_{A}$ and $s_{B}$ to maximize the total social welfare.

The optimal recycling fee and treatment subsidy are obtained from the following first-order conditions:

$$
\begin{gathered}
\frac{\partial W}{\partial t_{A}}=-\frac{a_{A}+t_{A}-c-2 \theta}{4 b}=0 \\
\frac{\partial W}{\partial t_{B}}=-\frac{a_{B}+t_{B}-c-2 \theta}{4 b}=0 \\
\frac{\partial W}{\partial s_{A}}=\frac{\left(\theta-s_{A}\right)}{\rho}=0
\end{gathered}
$$




$$
\frac{\partial W}{\partial s_{B}}=\frac{\left(\theta-s_{B}\right)}{\rho}=0
$$

From Equations (50)-(53), $\hat{t}_{i}^{D}$ and $\hat{s}_{i}^{D}$ are (denoted by $D$ on superscript for centralized policy with discriminatory rate)

$$
\begin{gathered}
\hat{t}_{A}^{D}=c+2 \theta-a_{A}>0, \text { if }\left(a_{A}-c\right) / 2<\theta \\
\hat{t}_{B}^{D}=c+2 \theta-a_{B}>0, \text { if } \frac{a_{B}-c}{2}<\theta \\
\hat{s}_{A}^{D}=\hat{s}_{B}^{D}=\theta
\end{gathered}
$$

From Equation (54), we have the following proposition.

Proposition 6. Under unilateral transboundary pollution, when the central government adopts a policy of adapting to local conditions, the recycling fee set by it will be equal to the level of no unilateral transboundary pollution. At the same time, it can correct the situation where the local government in Region A sets the recycling fee lower than the overall society.

When there is no unilateral cross-border pollution, the local government's policies will be returned to maximize local social welfare under the conditions of local conditions. Therefore, the optimal environmental policy will be the same as the local government's individual standards. Similarly, when there is unilateral pollution, because the central government takes local welfare into consideration in both regions, the environmental damage in Region B caused by unilateral transboundary pollution in Region A will be corrected, thereby making the overall social welfare improved.

\section{Conclusions and Remarks}

In economic theory literature, the government's policy objectives are usually set to maximize overall social welfare. This is a suitable way to discuss the policy formulation of the Taiwan Foundation Management Committee. However, the waste recycling system that has been constructed in China was mainly dominated by local governments before the amendment of Regulations in 2011. The central government has not intervened, and so the situation is determined by local decentralization. After the amendment of Regulations, the recycling policy is led by the central government and is consistent across the country.

In this study, under the existence of unilateral cross-border environmental pollution in two regions, a complete information dynamic game theory is constructed to discuss the environmental policy formulation of the central government by two local governments. As a result, it was found that the spillover effect will reduce the level of social welfare. At the same time, the intervention of the central government and the adoption of policies tailored to local conditions will be conducive to the improvement of social welfare. This result implies that the central government's environmental policy should be more flexible. At the same time, environmental policies are formulated by considering factors such as market conditions, production conditions, and spillover effects in different regions.

However, this study simply assumes that the market in the two regions is the exclusive market structure, and the difference between the two regions is only the difference in market size and pollution spillover coefficient. Considering suggestions for future research directions, first, it could be extended to the market competition analysis of $\mathrm{N}$ producers; second, it could explore the impact of the competition of $\mathrm{M}$ resource recyclers on the market equilibrium; third, it could discuss the heterogeneous demand function and the influence of policy choice; and finally, policy formulation under the incomplete information of the central government could be considered.

Author Contributions: Formal analysis, C.-H.L., P.-S.K., and J.-H.K.; funding acquisition, C.-H.L.; investigation, P.-S.K. and J.-H.K.; methodology, J.-Y.L.; supervision, Y.-L.W.; writing—original draft, P.-S.K.; writing-review and editing, Y.-L.W. All authors have read and agreed to the published version of the manuscript.

Funding: This research received no external funding.

Conflicts of Interest: The authors declare no conflict of interest. 


\section{References}

1. Housman, R.F. Book Chapter "International Environmental Law and Industrial Ecology". In The Greening of Industrial Ecosystems; National Academy Press: Washington, DC, USA, 1994. Available online: https: //www.nap.edu/read/2129/chapter/11 (accessed on 15 May 2020).

2. Coase, R.H. The Problem of Social Cost. J. Law Econ. 1960, 56, 837-877. [CrossRef]

3. Federal Environmental Ministry (FEM). Environmental Policy in Germany; FEM: Berlin, Germany, 1994.

4. Hotta, Y.; Kojima, S. Policy Framework for International Collaboration Towards Sustainable Resource Circulation and Management in Asia. In Greening Governance in Asia-Pacific; The Fourth IGES White Paper; Institute for Global Environmental Strategies: Kanagawa, Japan, 2011. Available online: https://www. scribd.com/document/107114676/Greening-Governance-in-Asia-Pacific-IGES-White-Paper-IV (accessed on 15 May 2020).

5. Totoki, Y.; Hotta, Y.; Suzuki-Aoki, C.; Santo, A.; Kojima, S. Greening the Trade of Recyclable Materials: Recycling Certification for Improved E-waste Management in East Asia. In Greening Integration in Asia; the fifth IGES White Paper; Institute for Global Environmental Strategies: Kanagawa, Japan, 2015. Available online: https://www.iges.or.jp/en/pub/greening-integration-asia-how-regional/en (accessed on 15 May 2020).

6. Fan, K.S.; Lin, C.H.; Chang, T.C. Management and Performance of Taiwan's Waste Recycling Fund. J. Air Waste Manag. Assoc. 2005, 55, 74-582. [CrossRef] [PubMed]

7. Liu, M.L.; Liu, J.S.; Zhang, F. Guangxi Electronic Waste Recycling Status and Problems Analysis. Ind. Technol. Econ. 2009, 28, 24-27. (In Chinese)

8. Pigou, A.C. The Economics of Welfare; Macmillan and Co. Limited: London, UK, 1932.

9. Buchanan, J.M. External Diseconomies, Corrective Taxes, and Market Structure. Environ. Resour. Econ. 1969, 20, 129-146.

10. Smith, V.K. A Note on Effluent Charges and Market Structure. J. Environ. Econ. Manag. 1976, 2, 309-311. [CrossRef]

11. Barnett, A.H. The Pigouvian Tax Rule under Monopoly. Am. Econ. Rev. 1980, 70, 1037-1041.

12. Oates, W.E.; Strassmann, D.L. Effluent fees and market structure. J. Public Econ. 1984, 24, 29-46. [CrossRef]

13. Misiolek, W.S. Pollution control through price incentives: The role of rent seeking costs in monopoly markets. J. Environ. Econ. Manag. 1988, 15, 1-8. [CrossRef]

14. Simpson, R.D. Optimal Pollution Taxation in A Cournot Duopoly. Environ. Resour. Econ. 1995, 6, 359-369. [CrossRef]

15. Long, N.V.; Soubeyran, A. Selective Penalization of Polluters: An Inf-Convolution Approach. Econ. Theory 2005, 25, 421-454. [CrossRef]

16. Downing, P.B.; White, L.J. Innovation in Pollution Control. J. Environ. Econ. Manag. 1986, 8, $225-271$. [CrossRef]

17. Milliman, S.R.; Prince, R. Firm Incentives to Promote Technological Change in Pollution Control. J. Environ. Econ. Manag. 1989, 17, 247-265. [CrossRef]

18. Conrad, K.; Wang, J. The Effect of Emission Taxes and Abatement Subsidies on Market Structure. Int. J. Ind. Organ. 1993, 11, 499-518. [CrossRef]

19. Damania, D. Pollution Taxes and Pollution Abatement in An Oligopoly Supergame. J. Environ. Econ. Manag. 1996, 30, 323-336. [CrossRef]

20. Yin, X. Corrective Taxes under Oligopoly with Inter-firm Externalities. Environ. Resour. Econ. 2003, 26, 269-277. [CrossRef]

21. Lahiri, S.; Ono, Y. Relative Emission Standard versus Tax under Oligopoly: The Role of Free Entry. J. Econ. 2007, 91, 107-128. [CrossRef]

22. Fujiwara, K. Environmental Policies in A Differentiated Oligopoly Revisited. Resour. Energy Econ. 2009, 31, 239-247. [CrossRef]

23. Hsu, C.C.; Lee, J.Y.; Wang, L.F.S. Consumers Awareness and Environmental Policy in Differentiated Mixed Oligopoly. Int. Rev. Econ. Financ. 2017, 51, 444-454. [CrossRef]

24. Fullerton, D.; Kinnaman, T. Garbage, Recycling, and Illicit Burning or Dumping. J. Environ. Econ. Manag. 1995, 29, 78-91. [CrossRef] 
25. Fullerton, D.; Wolverton, A. The Case for a Two-Part Instrument Presumptive Tax and Environmental Subsidy; Environmental and Public Economics: Essays in Honor of Wallace E. Oates; Oates, W.E., Panagaria, A., Portney, P., Schwab, R., Eds.; Edward Elgar: Cheltenham, UK, 1999; pp. 32-57.

26. Palmer, K.; Wall, M. Optimal Policies for Solid Waste Disposal: Taxes, Subsidies, and Standard. J. Public Econ. 1997, 65, 193-205. [CrossRef]

27. Ludema, R.D.; Wooton, I. Cross-Border Externalities and Trade Liberalization: The Strategic Control of Pollution. Can. J. Econ. 1994, 27, 950-966. [CrossRef]

28. Copeland, B.R.; Taylor, M.S. Trade and Transboundary Pollution. Am. Econ. Rev. 1995, 85, 716-737.

29. Copeland, B.R. Pollution Content Tariffs, Environmental Rent Shifting and the Control of Cross-Border Pollution. J. Int. Econ. 1996, 40, 459-476. [CrossRef]

30. Antweiler, W.; Copeland, B.R.; Taylor, M.S. Is Free Trade Good for the Environment? Am. Econ. Rev. 2001, 91, 877-908. [CrossRef]

31. Benarroch, M.; Thille, H. Transboundary Pollution and the Gains from Trade. J. Int. Econ. 2001, 55, $139-159$. [CrossRef]

32. Lai, Y.B.; Hu, C.H. Trade Agreements, Domestic Environmental Regulation, and Transboundary Pollution. Resour. Energy Econ. 2008, 30, 209-228. [CrossRef]

33. Ferrara, I.; Missios, P.; Yildiz, H.M. Trading Rules and The Environment: Does Equal Treatment Lead to a Cleaner World? J. Environ. Econ. Manag. 2009, 58, 206-225. [CrossRef]

34. Bhattacharya, R.N.; Pal, R. Environmental Standards as Strategic Outcomes: A Simple Model. Resour. Energy Econ. 2010, 32, 408-420. [CrossRef]

35. Lapan, H.E.; Sikdar, S. Strategic Environmental Policy under Free Trade with Transboundary Pollution. Rev. Dev. Econ. 2011, 15, 1-18. [CrossRef]

36. Yang, Y.P.; Hsu, S.Y. Environmental Policy in an Open Economy: Transboundary Pollution and Local Pollution. Soochow J. Econ. Bus. 2015, 88, 45-72.

37. Cao, J.; Xu, J.Y.; Wang, H.; Zhang, X.M.; Chen, X.; Zhao, Y.; Schnoor, J.L. Innovating Collection Modes for Waste Electrical and Electronic Equipment in China. Sustainability 2018, 10, 1446. [CrossRef]

38. Shinkuma, T.; Managi, S. On the Effectiveness of A License Scheme for E-Waste Recycling: The Challenge of China And India. Environ. Impact Assess. Rev. 2010, 30, 262-267. [CrossRef]

39. Sugeta, H.; Shinkuma, T. International Trade in Recycled Materials in Vertically Related Markets. Environ. Econ. Policy Stud. 2012, 14, 357-382. [CrossRef]

40. Liu, H.; Wu, X.; Dou, D.; Tang, X.; Leong, G.K. Determining Recycling Fees and Subsidies in China's WEEE Disposal Fund with Formal and Informal Sectors. Sustainability 2018, 10, 2979. [CrossRef]

41. Liu, G.; Xu, Y.; Tian, T.; Wang, T.; Liu, Y. The Impacts of China's Fund Policy on Waste Electrical and Electronic Equipment Utilization. J. Clean. Prod. 2020, 251, 119582. [CrossRef]

42. Shih, H.S.; Cheng, C.B.; Chen, H.Y. Recycling Fund Management for A Cleaner Environment through Differentiated Subsidy Rates. J. Clean. Prod. 2019, 240, 118146. [CrossRef]

43. Ma, Q.; Qin, P.H.; Bai, Y.; Zeng, H. Strategies to Build the Environmental Management Coordination System for Span District in China. China Popul. Resour. Environ. 2008, 18, 133-138. (In Chinese)

(C) 2020 by the authors. Licensee MDPI, Basel, Switzerland. This article is an open access article distributed under the terms and conditions of the Creative Commons Attribution (CC BY) license (http://creativecommons.org/licenses/by/4.0/). 